\title{
Maternal and neonatal outcomes of placenta previa and placenta accreta: three years of experience with a two-consultant approach
}

This article was published in the following Dove Press journal:

International Journal of Women's Health

27 November 2013

Number of times this article has been viewed

\section{Gamal A Kassem ' \\ Ali K Alzahrani ${ }^{2}$ \\ 'Department of Obstetrics and Gynecology, ${ }^{2}$ Neonatal Intensive Care Unit, King Abdul-Aziz Specialist Hospital, Taif, Kingdom of Saudi Arabia}

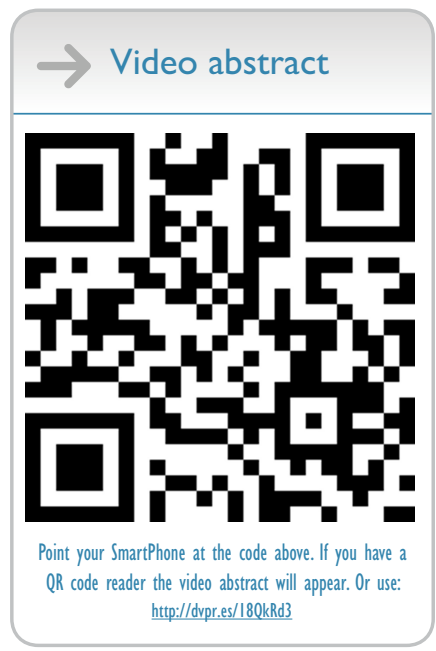

Correspondence: Gamal A Kassem Borg Al Seleem 3, Fourth Floor, Flat 6, Alqumia Street, Zagazig, Egypt Tel +20552353828

Email gamal-1960@hotmail.com
Objective: The aim of this retrospective cohort study was to evaluate maternal and neonatal outcomes in patients with placenta previa (PP) and placenta accreta (PA).

Methods: The study population comprised all patients who had a cesarean section for PP and PA at a tertiary referral hospital in Taif, Kingdom of Saudi Arabia, from December 2009 to December 2012. Maternal and neonatal data were obtained from medical records and the hospital database system. PA cases were managed by a multispeciality team, including two obstetric consultants.

Results: In total, 122 patients with PP were identified, with PA found in 25 cases. The median intraoperative blood loss in cases of PA was 2,000 (mean 3,000) $\mathrm{mL}$, with a loss of $\geq 2,000 \mathrm{~mL}$ occurring in $72 \%$, and $\geq 5,000 \mathrm{~mL}$ in $20 \%$. The median packed red blood cell transfusion requirement was 6 (mean 7.7) units, and $28 \%$ received $\geq 10$ units. Fetal growth restriction was diagnosed in two cases with known maternal medical disorders. Four cases (3.3\%) were diagnosed as small for gestational age. The mean birth weight of the neonates was at the 10th-50th percentile according to Hadlock fetal growth charts.

Conclusion: The presence of a second obstetric consultant among the multispeciality team during surgery for PA was associated with a reduction in blood loss and a decreased need for large-volume blood transfusion. The rate of fetal growth restriction/small for gestational age in PP was average, but the babies were relatively small (level 2 evidence).

Keywords: placenta previa, placenta accreta, maternal outcome, neonatal outcome

\section{Introduction}

In placenta previa (PP), the placenta is located over or very near the internal cervical os. ${ }^{1}$ Maternal and fetal morbidity and mortality from PP are considerable, and associated with high demands on health care resources. ${ }^{2-5}$ Given the rising incidence of cesarean section combined with increasing maternal age, the number of cases of PP and its complications, including placenta accreta (PA), will continue to increase.

Deficiency of the decidua basalis at the endometrial scar is thought to be the cause of PA. It is a form of morbidly adherent placenta with superficial uterine attachment. Placenta increta is characterized by placental penetration into the myometrium. Placenta percreta is the most severe form of morbidly adherent placenta, in which the placenta penetrates through the uterine wall and other pelvic organs, most commonly the bladder. Morbidly adherent placenta is a serious complication of pregnancy and is associated with massive intrapartum hemorrhage and high maternal morbidity and mortality. ${ }^{6,7}$ Surgery for morbidly adherent placenta is a considerable challenge, but it has been reported that maternal morbidity is reduced in women who deliver in a tertiary care hospital with a multispecialty care team. ${ }^{8}$ 
PP is known to be associated with prematurity. ${ }^{2,3}$ However, there is debate about the effect of PP on fetal growth; some studies have suggested that pregnancies with PP are at risk of low birth weight and a low Apgar score..$^{9-11}$ Some reports have shown high neonatal morbidity associated with PA. ${ }^{12}$ On the other hand, other studies did not observe adverse neonatal effects in such cases. ${ }^{13,14}$

The aim of the present study was to evaluate maternal and neonatal outcomes in cases of PP and PA over a 3-year period in a tertiary referral hospital.

\section{Materials and methods}

This retrospective cohort study was carried out at King AbdulAziz Specialist Hospital, a tertiary referral center in Taif, Kingdom of Saudi Arabia. After obtaining approval from the hospital ethics committee, the operating room log books were reviewed. All cases with a diagnosis of PP in the period from December 1, 2009 to December 1, 2012 were identified, with review of the relevant files in the medical records department. Laboratory investigations and histopathologic studies were reviewed via the hospital database system.

Data were collected on patient age, parity, gestational age at time of cesarean section, history of previous cesarean section(s), and degree of PP by ultrasound. The evaluation also included whether cesarean section was done electively or as an emergency, operative time, estimated blood loss during surgery, and units of packed red blood cell (PRBC) transfusion given. According to Wright et al, massive blood loss is defined as a loss of at least $5,000 \mathrm{~mL}$ during surgery, and high-volume blood transfusion is defined as at least 10 units of PRBCs. ${ }^{15} \mathrm{PA}$ is defined as the placenta being adherent to the uterine wall without easy separation and includes the spectrum of PA, placenta increta, and placenta percreta. The diagnoses were confirmed by histopathologic observation of placental invasion into the myometrium, clinical assessment of abnormal adherence of the placenta, or evidence of gross placental invasion at the time of surgery. ${ }^{16,17}$ In this paper, PA refers to all grades of morbidly adherent placenta unless otherwise specified.

Maternal morbidity, including urinary tract injuries, cesarean hysterectomy, and admission to the maternity highdependency unit or intensive care unit were also recorded. Preoperative and postoperative hospital stay was noted. Preoperative stay was calculated as total duration of hospital stay before surgery, either once or more if the patient was discharged and readmitted. Neonatal evaluation included neonatal birth weight, Apgar score at 1 and 5 minutes, admission to the neonatal intensive care unit, or any other complications.

\section{Protocol}

Surgery for cases with PP and PA strictly follows a local protocol. According to this protocol all cases of PP are managed by the consultant. Further, a second consultant is on standby inside the operating room to scrub immediately in the event of undue bleeding, difficulty, or a finding of PA. However, if PA is suspected preoperatively, the second consultant scrubs prior to surgery. This applies also for emergency cases. There is clear rotation for the first and second consultants. We can call it two-consultant approach. If PA is suspected, the woman is evaluated prior to surgery by the urology and vascular surgeons, with possible insertion of a ureteric stent, with the urology surgeon and vascular surgeon on standby in the operating room to scrub immediately if necessary. Anesthesia is performed by a consultant or by one of the anesthesia team in the presence of the consultant. Personal communication with blood bank personnel is done by the consultant or one of the team to ensure an adequate supply of blood and blood products. According to local departmental protocol, leaving the placenta in situ is not recommended. Interventional radiology facilities were not available in our hospital at the time of this study. The management protocol did not change during the study period.

According to the protocol, elective cesarean section was planned at 38 weeks or at 36-37 weeks if PA was suspected. All patients had gray scale ultrasound done by a team of obstetricians including an obstetrician or radiologist with subspecialist expertise in obstetric ultrasound. When PA was suspected, the case was examined again by a consultant. Magnetic resonance imaging was not done routinely. However, if PA was suspected, it is the option of the consultant to request it.

\section{Statistical analysis}

The relevant data were collected, summarized, tabulated, and analyzed using Statistical Package for the Social Sciences version 19 software (IBM, Armonk, NY, USA). $P \leq 0.05$ was considered to be statistically significant at a $95 \%$ confidence interval. The chi-square $\left(\chi^{2}\right)$, Yates' correction of $\chi^{2}$, and Fisher's exact tests were used to compare proportions. Analysis of variance (or $F$ test) was used to compare the means between more than two groups.

\section{Results \\ Maternal outcome}

A total of 122 patients with PP were enrolled in the study. According to operative findings, complete PP was confirmed in 58 cases, partial PP in 22 cases, marginal PP in 34 cases, 
and low lying PP in eight cases. PA was found in 25 patients, of them 19 presenting as PA, four as placenta increta, and two as placenta percreta. Histopathologic examination of the removed uteri confirmed PA, placenta increta, and placenta percreta in 13 , five, and one cases, respectively. The total number of deliveries during this period was 29,053, giving PP and PA rates of 4/1000 and 0.9/1000, respectively. Patient characteristics were as follows: a mean age of $32.9 \pm 5.06$ (range 18-42) years, mean parity of $3.7 \pm 2.52$ (range $0-10$ ), a history of previous cesarean section in $70(57.4 \%)$ cases, mean number of cesarean sections $1.4 \pm 1.58$, and a mean gestational age at the time of cesarean section of $35.8 \pm 2.38$ (range 26-40) weeks. One case was referred to our hospital at 40 weeks. She was 30 years of age, G4P3, had had no previous cesarean section, and ultrasound showed PP just reaching the internal os posteriorly.

PA was suspected on ultrasound in 21 of 25 cases and falsely diagnosed in six cases. Therefore, the sensitivity, specificity, positive predictive value, and negative predictive value was $83.33 \%, 94.17 \%, 80.65 \%$, and $95.10 \%$, respectively. Elective cesarean section was done in 66 patients (54.1\%) at 36-40 weeks. Emergency cesarean section was done in $56(45.9 \%)$ patients at 26-37 (mean 33.9) weeks. Mean operative time was $72.5 \pm 48.62$ (range 27-240) minutes. Mean estimated blood loss was 1,223.4 $\pm 1,376.35$ (range 300-6,000) $\mathrm{mL}$; estimated blood loss $<1,000 \mathrm{~mL}$ occurred in 75 cases $(61.5 \%) ; 1,000-1,999 \mathrm{~mL}$ in $20(16.4 \%) ; 2,000 \mathrm{~mL}$ in $12(9.8 \%) ; 3,000 \mathrm{~mL}$ in six $(4.9 \%) ; 4,000 \mathrm{~mL}$ in three $(2.5 \%), 5,000 \mathrm{~mL}$ in two $(1.6 \%)$; and $6,000 \mathrm{~mL}$ in four (2.5\%) patients. The mean PRBC transfusion requirement was $4.5 \pm 4.71$ (range $0-28$ ) units in 70 patients $(57.4 \%$ ); $1-4$ units in 48 patients $(39.3 \%), 5-9$ units in 14 patients (11.5\%), and $\geq 10$ units in eight patients (3.3\%). The amounts of blood loss and units of PRBC transfusion required by patients with PA are shown in Figures 1 and 2. The median estimated blood loss in PA was 2,000 mL.

Maneuvers done to control hemorrhage included multiple hemostatic sutures, bilateral uterine artery ligation, use of an intrauterine balloon, and internal iliac artery ligation. Cesarean hysterectomy was done in 24 patients (18\%; three of these patients had PP without PA and 21 had PP with PA). Urinary tract injuries occurred in 12 patients $(9.8 \%)$. The mean preoperative hospital stay was $15.4 \pm 17.72$ (range 0-70) days. Forty patients $(32 \%)$ were admitted to the maternity highdependency unit and $12(9.8 \%)$ were admitted to the intensive care unit. Mean postoperative hospital stay was $4.9 \pm 1.83$, and postoperative hospital stay was more than 5 days in $22(18 \%)$ patients. There was no maternal mortality.

A comparison of patients having PP with and without PA is shown in Table 1. The risk of PA in relation to previous cesarean section was as follows: one previous cesarean section $(n=21)$, two previous cesarean sections $(n=19)$, three previous cesarean sections $(n=10)$, four previous cesarean sections ( $\mathrm{n}=16)$, and five or more previous cesarean sections $(\mathrm{n}=4)$, representing a PA rate of $9.5 \%, 31.6 \%, 50 \%, 50 \%$, and $50 \%$, respectively.

\section{Neonatal outcome}

The neonatal outcome is shown in Table 2. Four babies $(3.3 \%)$ were diagnosed as small for gestational age. All

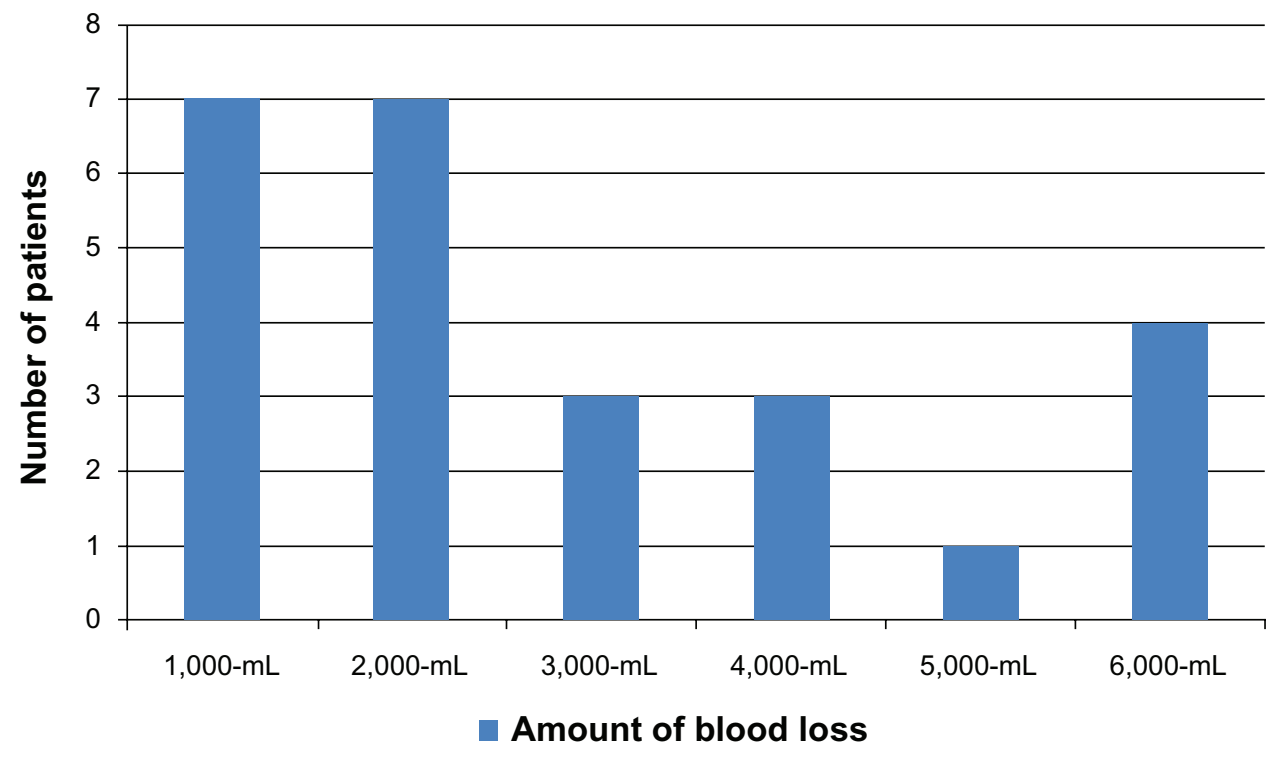

Figure I Intraoperative blood loss in patients with placenta accreta $(n=25)$. 


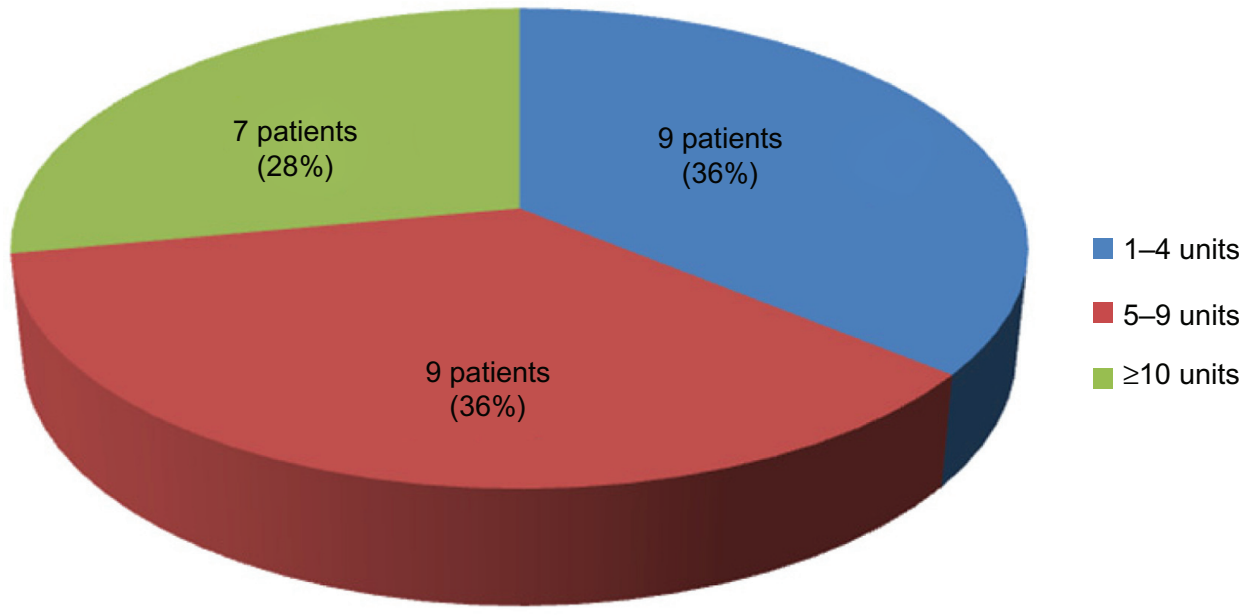

Figure 2 Units of packed red blood cells transfusion required in patients with placenta accreta $(n=25)$.

had a birth weight below the 10th percentile but no clear antenatal sonographic evidence of growth lag. Two neonates were diagnosed as having fetal growth restriction. The first was the baby of a 43-year-old G6P4+1 with one previous cesarean section who was known to have end-stage renal failure and was undergoing dialysis. She was delivered at 32 weeks by emergency cesarean section. The weight of the baby was $0.88 \mathrm{~kg}$. The second case was the baby of a 38 -yearold primigravida known to have chronic hypertension who was delivered by elective cesarean section at 37 weeks. The

Table I Comparison of maternal outcome in women having PP with and without PA $(n=122)$

\begin{tabular}{|c|c|c|c|c|}
\hline Variable & $\begin{array}{l}\text { PP without PA } \\
(n=97)\end{array}$ & $\begin{array}{l}\text { PP with PA } \\
(n=25)\end{array}$ & $\begin{array}{l}\text { Significance } \\
\text { test }\end{array}$ & $P$-value \\
\hline Age (years) (mean $\pm S D)$ & $32.4 \pm 5.03$ & $35.2 \pm 4.60$ & $t=2.5$ & 0.002 \\
\hline Parity (mean $\pm S D)$ & $3.5 \pm 2.55$ & $4.9 \pm 2.46$ & $t=2.4$ & 0.002 \\
\hline \multicolumn{5}{|l|}{ History of previous CS } \\
\hline Patients (n, \%) & $46(47.4 \%)$ & $24(96 \%)$ & $\chi^{2}=19.2$ & $<0.000$ I \\
\hline Mean number of CS $( \pm S D)$ & $1.0 \pm 1.39$ & $2.8 \pm 1.4$ & $t=5.7$ & $<0.00$ I \\
\hline \multicolumn{5}{|l|}{ Grade of PP } \\
\hline Major (complete and partial) (n, \%) & $55(56.7 \%)$ & $25(100 \%)$ & $\chi^{2}=16.5$ & $<0.000$ I \\
\hline Minor (marginal and low lying) (n, \%) & $42(40.3 \%)$ & $0(0.0 \%)$ & $\chi^{2}=14.8$ & $<0.000$ I \\
\hline Emergency surgery $(\mathrm{n}, \%)$ & $49(50.5 \%)$ & $7(28 \%)$ & $\chi^{2}=4.0$ & 0.042 \\
\hline Elective surgery $(n, \%)$ & $48(49.5 \%)$ & $18(72 \%)$ & $\chi^{2}=4.1$ & 0.043 \\
\hline Gestational age at time of delivery (weeks) (mean $\pm S D$ ) & $35.7 \pm 2.56$ & $36.5 \pm 1.38$ & $t=1.67$ & 0.045 \\
\hline Cesarean hysterectomy $(\mathrm{n}, \%)$ & $3(3.1 \%)$ & $21(84 \%)$ & $\chi^{2}=71.2$ & $<0.000$ I \\
\hline Urinary tract injuries $(n, \%)$ & $4(4.1 \%)$ & $8(32 \%)$ & $\chi^{2}=14.2$ & $<0.000$ I \\
\hline $\mathrm{EBL}$, mean $\pm \mathrm{SD}(\mathrm{mL})$ & $796.6 \pm 813.76$ & $2,984 \pm 1,685.39$ & $t=2.5$ & 0.001 \\
\hline \multicolumn{5}{|l|}{ PRBC transfusion } \\
\hline Patients receiving transfusion $(\mathrm{n}, \%)$ & $45(46.4 \%)$ & $25(100 \%)$ & $\chi^{2}=23.4$ & $<0.000 \mathrm{I}$ \\
\hline \multicolumn{5}{|l|}{ Units } \\
\hline Range & $0-10$ & $2-28$ & & \\
\hline Mean \pm SD & $1.3 \pm 2.89$ & $7.7 \pm 6.42$ & $t=2.23$ & 0.012 \\
\hline$\geq 10$ units & I (I\%) & $7(28 \%)$ & $\begin{array}{l}\text { Fisher's } \\
\text { exact test }\end{array}$ & $<0.000$ I \\
\hline Operative time (minutes) (mean $\pm \mathrm{SD}$ ) & $57.2 \pm 30.29$ & $146.3 \pm 50.05$ & $t=2.9$ & $<0.000$ I \\
\hline Admission to maternity HDU (n, \%) & 15 (I5.5\%) & $25(100 \%)$ & $\chi^{2}=64.5$ & $<0.000$ I \\
\hline Admission to ICU $(\mathrm{n}, \%)$ & $2(2.1 \%)$ & $10(40 \%)$ & $\chi^{2}=28.1$ & $<0.000$ I \\
\hline Postoperative hospital stay (days), (mean \pm SD) & $4.4 \pm 0.67$ & $7.1 \pm 3.01$ & $t=2.07$ & 0.013 \\
\hline Hospital stay $>5$ days $(n, \%)$ & $7(7.2 \%)$ & $17(68 \%)$ & $\chi^{2}=42.7$ & $<0.000$ I \\
\hline
\end{tabular}

Abbreviations: CS, cesarean section; HDU, high-dependency unit; ICU, intensive care unit; EBL, estimated blood loss; PRBC, packed red blood cells; SD, standard deviation; PA, placenta accreta; PP, placenta previa. 


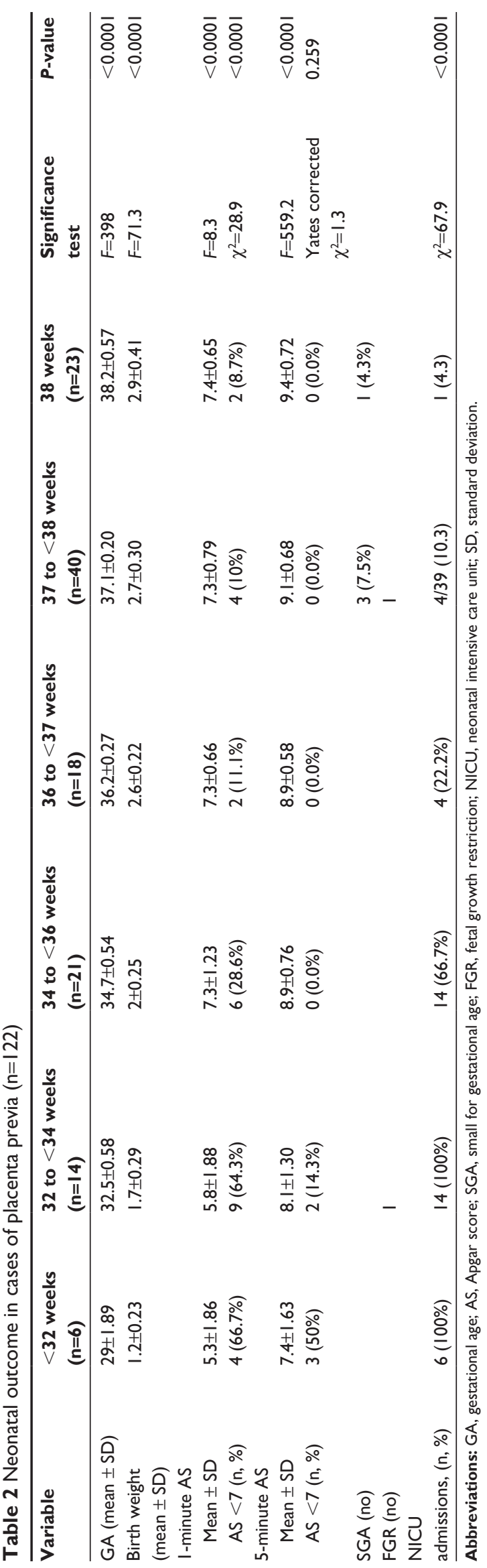

weight of the baby was $1.5 \mathrm{~kg}$. One patient was referred to our hospital as complete PP and intrauterine fetal death. She was a 34-year-old G13P8+4 known to have pregestational insulin-dependent diabetes mellitus.

Table 3 compares the neonatal outcomes in patients having PP with and without PA and delivered at $37<38$ weeks. A comparison between other gestational age groups was not done because of the small number of patients with PA.

\section{Discussion}

The present study indicates that maternal morbidity is significantly increased if PP is complicated by PA (level 2+ evidence). This is already described in the literature..$^{2-8}$ However, we also observed a slight reduction in massive blood loss and high-volume blood transfusion in comparison with other studies (level 2 evidence). The median estimated blood loss as a result of PA in our study was 2,000 mL (mean approximately $3,000 \mathrm{~mL}$ ), with a loss of $\geq 2,000 \mathrm{~mL}$ in $72 \%$ and a loss of $\geq 5,000 \mathrm{~mL}$ in $20 \%$. In addition, the median PRBCs transfusion required was 6 units (mean 7.7 units, with $28 \%$ receiving $\geq 10$ units). Wright et al reported a median blood loss of 3,000 mL and a median PRBCs transfusion requirement of 5 units in 77 patients undergoing hysterectomy for PA. ${ }^{15}$ Another study of 66 patients with PA reported a mean of 10 units, a median of 6.5 units, $39 \%$ of patients requiring $\geq 10$ PRBC units, and $11 \%$ requiring $\geq 20$ units. ${ }^{18}$ There is global consensus that women with PA should undergo surgery performed by an experienced team including an obstetric surgeon and other surgical specialists including urologists, general surgeons, gynecologic oncologists, and an interventional radiologist. ${ }^{19}$ Although we have no gynecologic oncology surgeon or facilities for interventional radiology in our hospital, we have had comparable outcomes. The presence of a second obstetric consultant among the multispecialty team may help in taking rapid action to control bleeding and in taking the decision for hysterectomy.

Gray scale ultrasonography is usually sufficient to diagnose PA, ${ }^{19}$ with a reported sensitivity of $77 \%-87 \%$, specificity of $96 \%-98 \%$, a positive predictive value of $65 \%-93 \%$, and a negative predictive value of $98 \% .^{20,21}$ Our figures are comparable at $83.33 \%, 94.17 \%, 80.65 \%$, and $95.10 \%$, respectively. A recent Cochrane review reported a sensitivity and specificity of $90.30 \%$ and $93.81 \%$, respectively. ${ }^{22}$ Because there are definite false positives and negatives in our study as well as others, care must be taken during surgery.

As shown in Table 1, patients with PA are older and have higher parity. We observed also that $96 \%$ of patients 
Table 3 Comparison between neonatal outcome in cases of placenta previa with and without PA at 37 to $<38$ weeks ( $n=40$ )

\begin{tabular}{|c|c|c|c|c|}
\hline Variable & $\begin{array}{l}\text { Without PA } \\
(n=25)\end{array}$ & $\begin{array}{l}\text { With PA } \\
(n=15)\end{array}$ & $\begin{array}{l}\text { Significance } \\
\text { test }\end{array}$ & $P$-value \\
\hline Gestational age (mean \pm SD) & $37.1 \pm 0.21$ & $37.1 \pm 0.21$ & $t=1.52$ & 0.820 \\
\hline Birth weight $($ mean $\pm S D)$ & $2.6 \pm 0.35$ & $2.7 \pm 0.25^{*}$ & $t=0.97$ & 0.634 \\
\hline \multicolumn{5}{|l|}{ I-minute Apgar score } \\
\hline$($ Mean $\pm S D)$ & $7 \pm 1.32$ & $7.5 \pm 0.75$ & $t=1.24$ & 0.065 \\
\hline AS $<7$ & $3(12 \%)$ & I (6.7\%) & $\begin{array}{l}\text { Fisher's } \\
\text { exact test }\end{array}$ & 1.000 \\
\hline \multicolumn{5}{|l|}{ 5-minute Apgar } \\
\hline$($ Mean $\pm S D)$ & $9 \pm 0.78$ & $9.3 \pm 0.51$ & $t=1.33$ & 0.042 \\
\hline AS $<7$ & $0(0 \%)$ & $0(0 \%)$ & & \\
\hline SGA & $3(12 \%)$ & I (6.7\%) & $\begin{array}{l}\text { Fisher's } \\
\text { exact test }\end{array}$ & 1.000 \\
\hline IUFD & 0 & 1 & $\begin{array}{l}\text { Fisher's } \\
\text { exact test }\end{array}$ & 0.375 \\
\hline
\end{tabular}

Note: *Only 14 patients, one patient presented with IUFD.

Abbreviations: AS, Apgar score; SGA, small for gestational age; IUFD, intrauterine fetal death; PA, placenta accreta; SD, standard deviation.

with PA in this study had a history of previous cesarean section with a mean number of 2.8 , compared with $47.4 \%$ of patients with a mean number of one cesarean section in the absence of PA. This difference is statistically significant (level $2+$ evidence). The risk of PA increases with increasing numbers of repeat cesarean sections, as shown in Figure 3. Indeed, the increased rate of PA in the last decade is probably a result of rising cesarean section rates. ${ }^{23}$ Therefore, it would be reasonable to consider stringent measures to reduce the rate of primary and repeat cesarean sections without increasing maternal-fetal compromise. Many strategies are proposed, among them reducing cesarean sections upon maternal request and encouraging a trial of vaginal delivery after cesarean section. Counseling of such patients should include the remote complications of repeat cesarean section, such as PA. ${ }^{24}$

Neonatal morbidity in our study was also significant. About half of our patients were delivered before 37 weeks and more than $28 \%$ of newborns were admitted to the neonatal intensive care unit. We also observed a low 1-minute Apgar score. However, the 5-minute Apgar score was improved, and only $4.1 \%$ had a score $<7$. Morbidity was more marked before 34 weeks.

We noted that there was a progressive decrease in neonatal morbidity in the form of improving Apgar scores and fewer admissions to the neonatal intensive care unit as gestation advanced. In an attempt to avoid emergent surgery for PA, some institutions justify elective surgery at $34-35$ weeks, ${ }^{25}$

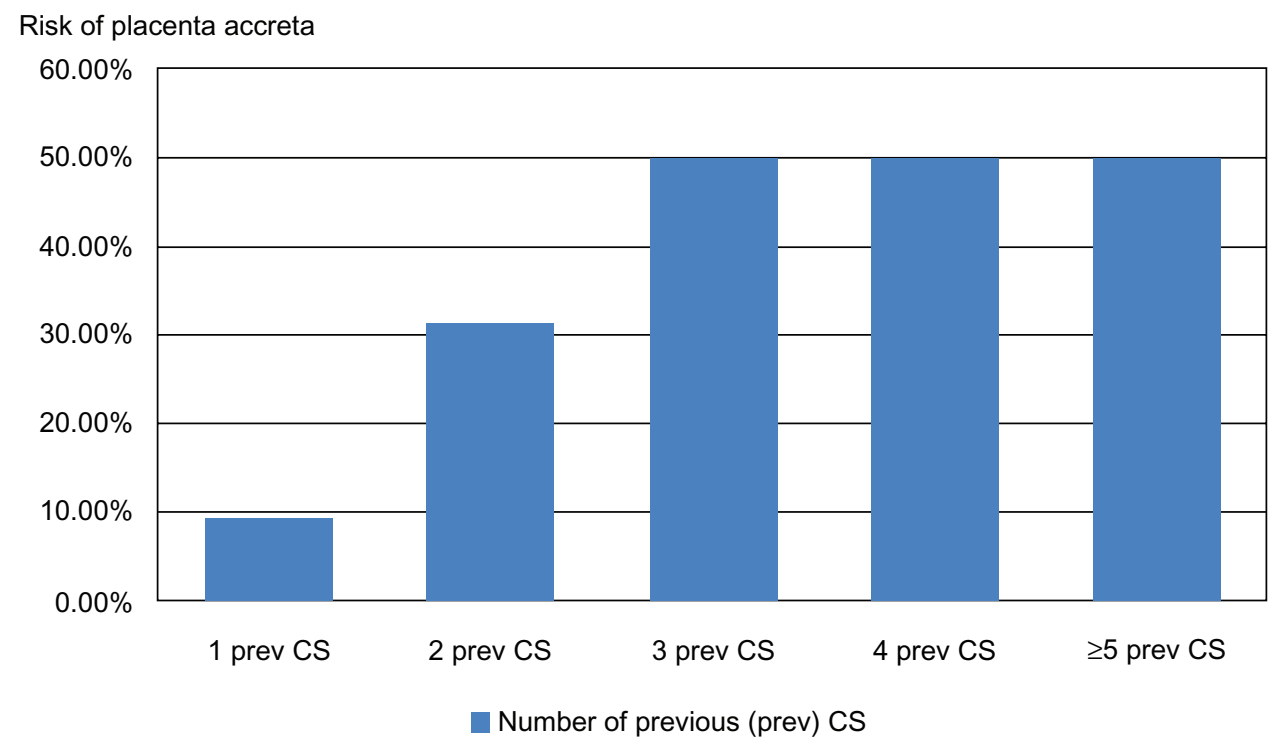

Figure 3 Risk of placenta accreta in patients with placenta previa and previous CS. Abbreviation: CS, cesarean section. 
arguing that this practice is not associated with increased neonatal morbidity. As shown in Table 3, waiting from 34.7 weeks (34 weeks +5 days) until 36.2 weeks ( 36 weeks +1.4 days) resulted in an increased mean neonatal weight of $600 \mathrm{~g}$ and a reduction in neonatal intensive care unit admissions from $66.7 \%$ to $22.2 \%$ (level $2+$ evidence). Therefore, waiting until 36 weeks could decrease neonatal morbidity in our population (grade $\mathrm{C}$ recommendation). However, the obstetrician must weigh the risks of neonatal prematurity against the benefits of a planned delivery.

Regarding the relationship between PP and fetal growth, there were two cases of fetal growth restriction. Fetal compromise in both cases could be explained by associated maternal medical disorders. Another four cases (3.3\%) were diagnosed as small for gestational age. The reported rate of fetal growth restriction/small for gestational age in the literature ranges from $3 \%$ to $5 \%{ }^{26}$ Therefore, we have no clear evidence to implicate PP as a cause of fetal growth restriction/small for gestational age. However, we observed that the mean birth weight of neonates in all groups was between the 10th and 50th percentiles according to Hadlock fetal growth charts, ${ }^{27}$ so these babies were only relatively smaller (level 2 evidence). We found no significant difference in neonatal outcome in PP with or without PA (level 2+ evidence).

The strengths of this study are that the patient files were reviewed by the authors themselves, the PP management protocol did not change during the study period, and the authors were working in the hospital during the study, and some cases were managed by them. However, the study has some limitations, ie, it was retrospective in nature and included a relatively small number of patients. Further, the study was conducted in a tertiary referral center with 24-hour availability of services. The availability of two obstetric consultants may not be feasible at all times in other hospitals.

\section{Conclusion}

In conclusion, in view of the increased risk of maternal morbidity, PA should be excluded in every case of PP, especially in those with risk factors such as previous uterine surgery, high parity, and advanced maternal age. If available, a second consultant should share in the surgery for PA. Elective delivery of patients with PA at 36 weeks instead of 34 weeks should be considered unless there is maternal risk (grade $\mathrm{C}$ recommendation). At present, there is no need to consider antenatal fetal surveillance programs for fetal growth restriction in women with PP/PA (grade C recommendation).

\section{Acknowledgments}

The authors thank Dr Ahmed Saad Ali (Head of Obstetrics and Gynecology) and Dr Rady Mahmoud (Specialist in Obstetrics and Gynecology) at Taif, King Abudul-Aziz Specialist Hospital, for their help with this research.

\section{Disclosure}

The authors report no conflicts of interest in this work.

\section{References}

1. Leveno KJ, Alexander JM, Bloom SL, et al. Placenta previa. In: Williams' Manual of Pregnancy Complications. 23rd ed. New York, NY: McGraw-Hill; 2013.

2. McShane P, Heyl P. Maternal and perinatal morbidity resulting from placenta previa. Obstet Gynecol. 1985;65:176-182.

3. Frederiksen FC, Glassenberg R, Stika CS. Placenta previa: a 22-year analysis. Am J Obstet Gynecol. 1999;180:1432-1437.

4. Faiz AS, Anath CV. Etiology and risk factors for placenta previa: an overview and meta-analysis of observational studies. J Matern Fetal Neonatal Med. 2003;13:175-190.

5. Wu S, Kocherginsky M, Hibbard J. Abnormal placentation: twenty-year analysis. Am J Obstet Gynecol. 2005;192:1458-1461.

6. Chou M. Prenatal diagnosis and perinatal management of placenta previa accreta: past, present and future. Taiwanese Journal of Obstetrics and Gynecology. 2004;43:64-71.

7. Heller DS. Placenta accreta and percreta. Surg Pathol. 2013;6:181-197.

8. Eller AG, Bennett MA, Sharshiner M, et al. Maternal morbidity in cases of placenta accreta managed by multidisciplinary care team compared with standard obstetric care. Obstet Gynecol. 2011;117(2 Pt 1): 331-337.

9. Ananth CV, Demissie K, Smulian JC, Vintzileos AM. Relationship among placenta previa, fetal growth restriction, and preterm delivery: a population-based study. Obstet Gynecol. 2001;98:299-306.

10. Pariente G, Sheiner E. Reply: placenta previa and perinatal mortality. Arch Gynecol Obstet. 2011;284:1049.

11. Nørgaard LN, Pinborg A, Lidegaard Ø, Bergholt T. A Danish national cohort study on neonatal outcome in singleton pregnancies with placenta previa. Acta Obstet Gynecol Scand. 2012;91:546-551.

12. Balayla J, Bondarenko HD. Placenta accreta and the risk of adverse maternal and neonatal outcomes. J Perinat Med. 2013;41: 141-149.

13. Harper LM, Odibo AO, Macones GA, Crane JP, Cahill AG. Effect of placenta previa on fetal growth. Am J Obstet Gynecol. 2010;203:330.

14. Rosenberg T, Pariente G, Sergienko R, Wiznitzer A, Sheiner E. Critical analysis of risk factors and outcome of placenta previa. Arch Gynecol Obstet. 2011;284:47-51.

15. Wright JD, Pri-Paz S, Herzog TJ, et al. Predictors of massive blood loss in women with placenta accreta. Am J Obstet Gynecol 2011;205:38.

16. Oyelese Y, Smulian JC. Placenta previa, placenta accreta, and vasa previa. Obstet Gynecol. 2006;107:927-941.

17. Wortman AC, Alexender JM. Placenta accreta, increta and percreta. Obstet Gynecol Clin North Am. 2013;40:137-154.

18. Stotler B, Padmanabhan A, Devine P, Wright J, Spitalnik SL, Schwartz J. Transfusion requirements in obstetric patients with placenta accreta. Transfusion. 2011;51:2627-2633.

19. American College of Obstetricians and Gynecologists. Committee opinion no 529: placenta accreta. Obstet Gynecol. 2012;120:207-211.

20. Warshak CR, Eskander R, Hull AD, et al. Accuracy of ultrasonography and magnetic resonance imaging in the diagnosis of placenta accreta. Obstet Gynecol. 2006;108(3 Pt 1):573-581.

21. Comstock CH, Love JJ Jr, Bronsteen RA, et al. Sonographic detection of placenta accreta in the second and third trimesters of pregnancy. Am J Obstet Gynecol. 2004;190:1135-1140. 
22. D'Antonio F, Iacovella C, Bhide A. Prenatal identification of invasive placentation using ultrasound: a systematic review and meta-analysis. Ultrasound Obstet Gynecol. August 13, 2013. [Epub ahead of print.]

23. Morlando M, Sarno L, Napolitano R, et al. Placenta accreta: incidence and risk factors in an area with a particularly high rate of cesarean section. Acta Obstet Gynecol Scand. 2013;92:457-460.

24. American College of Obstetricians and Gynecologists. ACOG practice bulletin no. 115: vaginal birth after previous cesarean delivery. Obstet Gynecol. 2010;116(2 Pt 1):450.
25. Warshak CR, Ramos GA, Eskander R, et al. Effect of predelivery diagnosis in 99 consecutive cases of placenta accreta. Obstet Gynecol. 2010;115:65-69.

26. Romo A, Carceller R, Tobajas J. Intrauterine growth retardation; epidemiology and etiology. Pediatr Endocrinol Rev. 2009;6 Suppl 3: 332-336.

27. Hadlock FP, Harrist RB, Martinez-Poyer J. In utero analysis of fetal growth: a sonographic weight standard. Radiology. 1991;181: 129-133.

\section{Publish your work in this journal}

The International Journal of Women's Health is an international, peerreviewed open-access journal publishing original research, reports, editorials, reviews and commentaries on all aspects of women's healthcare including gynecology, obstetrics, and breast cancer. The manuscript management system is completely online and includes a very quick and fair peer-review system, which is all easy to use. Visit http://www.dovepress.com/testimonials.php to read real quotes from published authors.

Submit your manuscript here: http://www.dovepress.com/international-journal-of-womens-health-journal 